\title{
Evaluation of bioequivalence of two enrofloxacin formulations after intramuscular administration in goats
}

\author{
Mohamed Hafez Aboubakr* \\ Department of Pharmacology, Faculty of Veterinary Medicine, Benha University, 13736 Moshtohor, Egypt
}

(Received: November 21, 2012; Revised: February 4, 2013; Accepted: February 22, 2013)

\begin{abstract}
The present study was planned to evaluate the bioequivalence of two commercial formulations of enrofloxacin, which have been marketed as $10 \%$ injectable solution after intramuscular administration at a single dose of $2.5 \mathrm{mg} / \mathrm{kg}$ body weight to 12 clinically healthy goats The study was carried out on the basis of crossover design. The two formulations were: Baytril as a reference product and Spectrama Vet as a test product. The plasma concentrations of enrofloxacin were measured by high performance liquid chromatography (HPLC) with UV detector. The pharmacokinetics of that data was performed using non-compartmental analysis. The maximum plasma concentration $\left(\mathrm{C}_{\max }\right)$, time to reach peak concentration $\left(\mathrm{T}_{\max }\right)$, area under concentration-time curve (AUC), elimination half-life $\left(\mathrm{t}_{0.5 \mathrm{el}}\right)$ were 1.14 and $1.05 \mu \mathrm{g} / \mathrm{mL}, 0.79$ and $0.83 \mathrm{~h}, 5.70$ and $5.79 \mu \mathrm{g} . \mathrm{h} / \mathrm{mL}, 5.19$ and $5.39 \mathrm{~h}$ for Baytril and Spectrama Vet, respectively. The $90 \%$ confidence interval for the mean ratio of $\mathrm{T}_{\max }, \mathrm{C}_{\max }$ and AUC were 94.72 116.2, 87.88 97.16 and 86.44 118.72\%, respectively. These values falls within the European Medicines Agency bioequivalence acceptance range of $80 \sim 125 \%$ for both $\mathrm{T}_{\max }$ and AUC and between $75 \sim 133 \%$ for $\mathrm{C}_{\max }$. In conclusion, Spectrama-Vet is bioequivalent to Baytril and both products can be used as interchangeable drug in veterinary medicine practice.
\end{abstract}

Keywords : bioequivalence, fluoroquinolones, HPLC, pharmacokinetics

\section{Introduction}

Enrofloxacin (ENR) is a derivative of quinolonecarboxylic acid classified into the group of broad spectrum antibacterial related to a second generation fluoroquinolones. It is widely used in veterinary medicine in cattle, pigs, poultry, fish, dogs and cats in the treatment of diseases caused by aerobic Gram-negative, Gram-positive bacteria and such pathogens as Mycoplasma, Chlamydia and Rickettsia [7]. It is mainly indicated for gastrointestinal, urogenital, skin and respiratory tract infections in various domestic animal species [29, 2]. It is metabolized to ciprofloxacin via de-ethylation of the ethyl group on the piperazine ring and mainly excreted as a parent drug and its metabolite by glomerular filtration and tubular excretion [37]. The mechanism of action of ENR is connected with its interfering with DNA synthesis by inhibiting DNA gyrase activity [40]. It has bactericidal activity at relatively low concentrations, high bioavailability following oral or parenteral administration in most animal species and it achieves good penetration into body tissues and fluids [10, 35]. In addition, ENR has a long serum half-life, making it suitable for administration once or twice daily.

The pharmacokinetic evaluation of enrofloxacin has been carried out in several animal species including chickens [30], pigs [4], rabbits [6, 14], fish [23, 26], sheep [20, 15], goats $[13,34]$, horses [18, 25], cows [22], dogs [24, 39] and calves [9]. Fluoroquinolones widespread application in human and food-producing animals has increased the risk of inducing pathogen resistance which may lead to therapy failure [7].

In this study the bioequivalence and differences in pharmacokinetics of two ENR formulations were established. The bioavailability and bioequivalence studies play an important role in determining therapeutic efficacy to register the generic drug products according to the U.S. Food and Drug Administration (FDA) regulations [8]. Bioequivalence is defined as statistically equivalent bioavailability between two products at the same molar dose of the therapeutic moiety under similar experimental conditions. Two products are said to be bioequivalent if they are pharmaceutically equivalents or pharmaceutical alternatives and if their rate and extent of absorption do not show a statistically significant difference [36]. Bioequivalence studies are designed to examine whether the systemic bioavailability of a test product and those of the reference product differ significantly. Following the relevant FDA and European Medicines Agency (EMEA) Guidelines, the statistical analysis should be based on the non-compart-

*Corresponding author

Tel: +201099874671 , Fax: +20132463074

E-mail: mohamedhafez19@yahoo.com 
mental parameters maximum plasma concentration $\left(\mathrm{C}_{\max }\right)$, time to reach peak concentration $\left(\mathrm{T}_{\max }\right)$ and the area under the plasma concentration-time curve (AUC), derived from the drug concentration-time curve. These values must be fall within the EMEA bioequivalence acceptance range of $80 \sim 125 \%$ for both $\mathrm{T}_{\max }$ and AUC and between $75 \sim 133 \%$ for $\mathrm{C}_{\max }$ [31].

The aim of this study was to evaluate bioequivalence of two different enrofloxacin injectable formulations after intramuscular (IM) administration of a single dose in goats.

\section{Materials and Methods}

\section{Drugs}

Two commercial enrofloxacin $10 \%$, injectable solutions were used in this study. Baytril manufactured by Bayer AG, Germany (as a reference formulation) and Spectrama Vet manufactured by Amoun Pharmaceutical Company, Egypt (as a test formulation). Enrofloxacin standard was purchased from Sigma Chemical Company (USA). The solvents (Baker, USA) used during the chromatographic analysis of the drug were high-performance liquid chromatography (HPLC) grade.

\section{Experimental animals}

Twelve clinically healthy non-pregnant, non-lactating native breed goats of 2 3 years old and weighting $23 \sim 29 \mathrm{~kg}$ body weight (BW) were used. Goats were kept indoors under good hygienic conditions, fed on alfalfa hay, green fodders, a concentrated mixture in a pelleted form and received water $a d$ libitum. Animals did not receive any medication in the last three weeks before the commencement of the study. Goats were determined to be healthy on the basis of a physical examination. The protocol of this study was performed in accordance with the guidelines set by the Ethical Committee of Benha University, Egypt.

\section{Experimental design and sample collection}

The study was conducted at a single dose two period crossover design. One day before injection of the products, the animals were individually weighed for dose adjustment and the reference product (Baytril) was administered to the first six animals and the test product (Spectrama-Vet) was administered to the second six animals. Each animal received a single IM dose of each formulation at a dose rate of $2.5 \mathrm{mg} / \mathrm{kg} \mathrm{BW}$ into the semimembranous muscle. After fifteen days of washout period, animals that received treatment with the reference formulation were administered test formulation and vice versa.

Blood samples $(4 \mathrm{~mL})$ were collected from jugular vein of each goat prior and at 5, 10, 15, 30 and $45 \mathrm{~min}$, and 1, 2, 4, $6,8,12$ and $24 \mathrm{~h}$ after ENR administration, into tubes containing heparin. Plasma was separated after centrifugation at $3,000 \times \mathrm{g}$ for $15 \mathrm{~min}$. The plasma was decanted, labeled, and frozen at $-20^{\circ} \mathrm{C}$ until analyzed by HPLC.

\section{Drug assay}

The concentrations of ENR in plasma were determined simultaneously by using HPLC with UV detection [24], after sample extraction [29]. In brief, $0.75 \mathrm{~mL}$ acetonitrile was added to $0.5 \mathrm{~mL}$ plasma in a test tube. After vortex mixing at high speed for $15 \mathrm{sec}$, the tube was centrifuged at $950 \times \mathrm{g}$ for $10 \mathrm{~min}$. The clear supernatant was collected and twice the volume of HPLC grade water was added. The aliquot was then filtered through a $0.22 \mu \mathrm{m}$ cellulose acetate membrane filter and $20 \mu \mathrm{L}$ of filtrate was injected into the HPLC system. The HPLC system (Shimadzu, Japan) consists of a pump (LC-10AD with CBM-20A system controller) with a low-pressure-gradient flow control valve (FCV-10AL) and a degasser (DGU-14A) to pump the mobile phase, an autosampler (SIL-10AD), and a column oven (CTO-10A). The detection was performed using an SPD-10Avp UV-VIS detector set at $278 \mathrm{~nm}$. The conditions for HPLC analysis were as follows. Column; $\mathrm{C}_{18}, 4 \times 250 \mathrm{~mm}$ (YMC, Shimadzu, Japan), Mobile phase; acetonitrile : methanol : HPLC water $(17: 3$ : $80, \mathrm{v} / \mathrm{v} / \mathrm{v})$, containing $0.4 \%$ triethylamine and $0.4 \%$ orthophosphoric acid $(85 \%, \mathrm{v} / \mathrm{v})$. The $\mathrm{pH}$ of the mobile phase was 2.5. The flow rate was $0.6 \mathrm{~mL} / \mathrm{min}$ at ambient temperature $\left(20^{\circ} \mathrm{C}\right)$. ENR was quantified from the respective peak areas and the concentrations in plasma samples were determined by means of calibration curves obtained on analysis of blank plasma samples spiked with enrofloxacin (external standards) and analyzed as described for the experimental samples. The limit of sensitivity and quantification for ENR was $0.01 \mu \mathrm{g} /$ $\mathrm{mL}$. Mean recovery for ENR from plasma was $>90 \%$. The method was found to be linear and reproducible in the concentration range of $0.01 \sim 5 \mu \mathrm{g} / \mathrm{mL}$.

\section{Pharmacokinetic analysis}

Pharmacokinetic parameters were determined for each individual goat. Plasma concentrations of the two formulations of ENR after a single IM administration were subjected to a non-compartmental analysis based on the statistical moment theory [17], using computerized program, WinNonlin 4.1 (Pharsight, USA). Values calculated following the IM administration were: AUC, area under the first moment curve (AUMC); the AUC and AUMC were calculated using trapezoidal rules, mean residence time (MRT, where MRT $=$ AUMC/ AUC), elimination rate constant $\left(\mathrm{k}_{\mathrm{el}}\right.$, calculated as the slope of the terminal phase of the plasma concentration curve) and terminal half-life $\left(t_{0.5}\right.$, where $\left.t_{0.5}=0.693 / \mathrm{k}_{\mathrm{el}}\right)$. Each individual curve of enrofloxacin over time was analyzed to determine the peak concentration $\mathrm{C}_{\max }$ (extrapolated from the curve), and the time to peak concentration $\mathrm{T}_{\max }$ was read from the data.

Statistical analysis on the pharmacokinetics parameters of ENR formulations were assessed by analysis variance (ANOVA). The differences were considered significant when $p<0.05$. All data are expressed as mean \pm SD.

\section{Results}

No local or systemic adverse reactions to Baytril and Spectrama-Vet occurred after a single IM administration. 
Table 1. Plasma concentrations of ENR $(\mu \mathrm{g} / \mathrm{mL})$ following a single intramuscular (IM) administration of $2.5 \mathrm{mg} / \mathrm{kg}$ body weight $(\mathrm{BW})$ in goats $(\mathrm{n}=12)$, values are means $\pm \mathrm{SD}$

\begin{tabular}{ccc}
\hline \hline \multirow{2}{*}{$\begin{array}{c}\text { Time post } \\
\text { administration }(\mathrm{h})\end{array}$} & \multicolumn{2}{c}{ Mean plasma concentration $(\mu \mathrm{g} / \mathrm{mL})$} \\
\cline { 2 - 3 } & $\begin{array}{c}\text { Baytril } \\
\text { (Reference) }\end{array}$ & $\begin{array}{c}\text { Spectrama Vet } \\
\text { (Test) }\end{array}$ \\
\hline 0.08 & $0.33 \pm 0.04$ & $0.37 \pm 0.08$ \\
0.16 & $0.45 \pm 0.04$ & $0.49 \pm 0.08$ \\
0.25 & $0.58 \pm 0.06$ & $0.61 \pm 0.10$ \\
0.5 & $0.88 \pm 0.07$ & $0.82 \pm 0.05$ \\
0.75 & $1.10 \pm 0.11$ & $0.99 \pm 0.06$ \\
1 & $1.00 \pm 0.08$ & $0.96 \pm 0.09$ \\
1.5 & $0.87 \pm 0.06$ & $0.82 \pm 0.07$ \\
2 & $0.73 \pm 0.07$ & $0.72 \pm 0.06$ \\
4 & $0.58 \pm 0.11$ & $0.55 \pm 0.08$ \\
6 & $0.41 \pm 0.07$ & $0.43 \pm 0.11$ \\
8 & $0.32 \pm 0.06$ & $0.36 \pm 0.10$ \\
10 & $0.27 \pm 0.05$ & $0.28 \pm 0.08$ \\
12 & $0.19 \pm 0.04$ & $0.20 \pm 0.07$ \\
24 & $\mathrm{ND}$ & $\mathrm{ND}$ \\
\hline
\end{tabular}

ND: not detected

The mean plasma concentrations of ENR following IM administration of $2.5 \mathrm{mg} / \mathrm{kg} \mathrm{BW}$ of the two formulations were presented in Table 1. Mean plasma concentration time profiles of the reference and tested formulations were shown graphically in Fig. 1. The concentration of ENR in goat's plasma were determined up to $12 \mathrm{~h}$ and were not detected

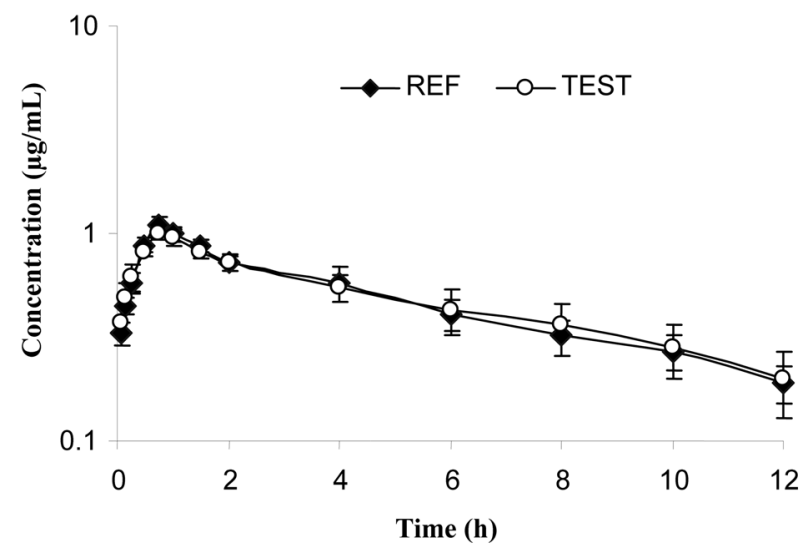

Fig. 1. Semi-Logarithmic graph depicting the time-concentration of two enrofloxacin formulations $(\checkmark)$ Reference and $(\bigcirc)$ Test, after a single IM administration of $2.5 \mathrm{mg} / \mathrm{kg} \mathrm{BW}$ in goats $(\mathrm{n}=12)$.

in all goats $24 \mathrm{~h}$ post single IM administration. The mean pharmacokinetics parameters of the reference and tested formulations given to goats were shown in Table 2. No significant differences were found among all the tested pharmacokinetics parameters between the two formulations. The $90 \%$ confidence interval for the mean ratio of $\mathrm{T}_{\max }, \mathrm{C}_{\max }$ and AUC of the reference and tested formulations were within the bioequivalence acceptance range and summarized in Table 3.

Table 2. Evaluation of bioequivalence of two formulation of enrofloxacin in goats

\begin{tabular}{lcccccc}
\hline \hline \multicolumn{1}{c}{ Parameters } & Reference & Test & $\begin{array}{c}90 \% \text { CI Lower } \\
\text { Upper }\end{array}$ & T/R (\%) & $\begin{array}{c}\text { Acceptable } \\
\text { range (\%) }\end{array}$ & Conclusion \\
\hline $\mathrm{C}_{\max }(\mu \mathrm{g} / \mathrm{mL})$ & $1.14 \pm 0.09$ & $1.05 \pm 0.04$ & $87.88 \sim 97.16$ & 92.24 & $75 \sim 133$ & $\mathrm{BE}$ \\
$\mathrm{T}_{\max }(\mathrm{h})$ & $0.79 \pm 0.10$ & $0.83 \pm 0.13$ & $94.72 \sim 116.20$ & 105.26 & $80 \sim 125$ & $\mathrm{BE}$ \\
$\mathrm{AUC}(\mu \mathrm{g} . \mathrm{h} / \mathrm{mL})$ & $5.70 \pm 0.85$ & $5.79 \pm 0.99$ & $86.44 \sim 118.72$ & 101.53 & $80 \sim 125$ & $\mathrm{BE}$ \\
\hline
\end{tabular}

BE: bioequivalence

Table 3. Pharmacokinetics parameters of ENR following a single IM of $2.5 \mathrm{mg} / \mathrm{kg} \mathrm{BW}$ in goats $(\mathrm{n}=12)$, values are means \pm SD

\begin{tabular}{llrr}
\hline \hline Parameter & Unit & Baytril (Reference) & Spectrama Vet (Test) \\
\hline $\mathrm{K}_{\mathrm{el}}$ & $\mathrm{h}^{-1}$ & $0.13 \pm 0.01$ & $0.13 \pm 0.03$ \\
$\mathrm{t}_{0.5 \mathrm{el}}$ & $\mathrm{h}$ & $5.19 \pm 0.53$ & $5.39 \pm 0.96$ \\
$\mathrm{C}_{\max }$ & $\mu \mathrm{g} / \mathrm{mL}$ & $1.14 \pm 0.09$ & $1.05 \pm 0.04$ \\
$\mathrm{~T}_{\max }$ & $\mathrm{h}$ & $0.79 \pm 0.10$ & $0.83 \pm 0.13$ \\
$\mathrm{AUC}$ & $\mu \mathrm{g} \cdot \mathrm{h} / \mathrm{mL}$ & $5.70 \pm 0.85$ & $5.79 \pm 1.00$ \\
$\mathrm{AUMC}$ & $\mu \mathrm{g} \cdot \mathrm{h}^{2} / \mathrm{mL}$ & $25.33 \pm 4.89$ & $26.73 \pm 6.63$ \\
$\mathrm{MRT}$ & $\mathrm{h}$ & $4.42 \pm 0.22$ & $4.57 \pm 0.34$ \\
$\mathrm{C}_{\max } / \mathrm{MIC}$ & Ratio & $11.38 \pm 0.86$ & $10.5 \pm 0.40$ \\
AUC/MIC & Ratio & $57.02 \pm 8.51$ & $57.90 \pm 9.98$ \\
\hline
\end{tabular}

$\mathrm{K}_{\mathrm{el}}$; elimination rate constant after IM administration, $\mathrm{t}_{0.5 \mathrm{el}}$; elimination half-life after oral administration, $\mathrm{C}_{\max }$; maximum plasma concentration, $\mathrm{T}_{\max }$; time to peak serum concentration, $\mathrm{C}_{\max }$ MIC; maximum serum concentration/minimum inhibitory concentration ratio, AUC/MIC; area under the plasma concentration-time curve/MIC ratio. AUC: area under the plasma concentration-time curve, AUMC: area under moment curve, MRT: mean residence time. 


\section{Discussion}

Fluoroquinolones are considered to be among the most effective drugs for the treatment of bacterial infections. Among them, ENR has been developed exclusively for use in veterinary medicine. To obtain maximal efficacy and to avoid development of resistance in commensally and pathogenic organisms, rational use of antimicrobial drugs should be based on the knowledge of the structures and biochemical characteristics of microorganisms and on the pharmacodynamic and pharmacokinetic properties of antimicrobial drugs [5].

After a single IM administration of two ENR injectable formulations at a dose rate of $2.5 \mathrm{mg} / \mathrm{kg} \mathrm{BW}$ to goats, we found that, maximum serum concentrations $\left(\mathrm{C}_{\max }\right)$ were 1.14 and $1.05 \mu \mathrm{g} / \mathrm{mL}$ being achieved at 0.79 and $0.83 \mathrm{~h}\left(\mathrm{~T}_{\max }\right)$ for Baytril and Spectrama Vet, respectively. The $\mathrm{C}_{\max }$ obtained in the present study were almost the same as that reported for pigs, $1.17 \mu \mathrm{g} / \mathrm{mL}$ [4]. These values were lower in animals given a single IM dose of $5 \mathrm{mg} / \mathrm{kg} \mathrm{BW}$ as reported in desert sheep and Nubian goats, 1.29 and $1.33 \mu \mathrm{g} / \mathrm{mL}$, respectively [15], and $2.8 \mu \mathrm{g} / \mathrm{mL}$ reported in goats [34]. The difference in the dose rate in these studies may contribute to the differences in the $\mathrm{C}_{\max }$.

The $T_{\max }$ achieved for the two formulations were agree with those reported by Haritova et al. [20] in sheep, $0.83 \mathrm{~h}$, and lower that reported in desert sheep and Nubian goats, 1.96 and $1.85 \mathrm{~h}$, respectively [15].

AUC is a useful index for biological availability of the active moiety of a drug formulation (extent of absorption). AUC in this study was 5.70 and $5.78 \mu \mathrm{g} . \mathrm{h} / \mathrm{mL}$ for reference and tested formulations, respectively; this value was lower than that reported in desert sheep and Nubian goats 7.86 and $7.55 \mu \mathrm{g} . \mathrm{h} / \mathrm{mL}$ respectively, [15] and higher than 2.09 and $2.60 \mu \mathrm{g} . \mathrm{h} / \mathrm{mL}$ reported in goats, respectively $[1,33]$.

Elimination half-lives $\left(\mathrm{t}_{0.5 \mathrm{el}}\right)$ of reference and tested formulations following IM administrations were 5.19 and $5.39 \mathrm{~h}$, respectively. This observation agreed with the data reported in lactating cows $5.9 \mathrm{~h}$, [22], longer than those reported in goats $(2.62,1.39$ and $1.51 \mathrm{~h}$, respectively [1, 15, 34]. Such differences in pharmacokinetics parameters were relatively common and frequently related to inter-species variation, assay methods used, the time between blood samplings, and/ or the health status and age of the animals [19].

Bioequivalence study is a test to assure the clinical efficacy of a generic versus brand drugs [8]. Bioequivalence refers to a comparison between generic formulations of a drug, or a product in which a change has been made in one or more of the ingredients or in the manufacturing process, and a reference dosage form of the same drug [3]. This bioequivalence study was carried out in healthy goats under controlled conditions using a crossover design. The bioequivalence ratios for mean $\mathrm{T}_{\max }, \mathrm{C}_{\max }$ and AUC (T/R) of Spectrama Vet versus the reference product Baytril were 105.26, 92.24 and 101.53 respectively. The $90 \%$ confidence interval for the mean ratio of $\mathrm{T}_{\max }, \mathrm{C}_{\max }$ and AUC were 94.72 116.2,
87.88 97.16 and 86.44 118.72\%, respectively. These values falls within the EMEA bioequivalence acceptance range of $80 \sim 125 \%$ for both $\mathrm{T}_{\max }$ and AUC and between $75 \sim 133 \%$ for $\mathrm{C}_{\max }[31]$.

Perhaps more than with other class of antimicrobial agents, dosage of fluoroquinolones should be based on the susceptibility of the bacterial target. As 'dose-dependent antimicrobial', clinical efficacy of the fluoroquinolones is dependent on dose and bacterial pathogen. Based on many in vitro and in vivo studies performed in humans and animals, it has been established that for concentration dependant antibacterial agents, such as fluoroquinolones, the AUC/minimum inhibitory concentraion (MIC) ratio is the most important factor in predicting efficacy, with the rate of clinical cure being greater than $80 \%$ when this ratio is higher that $100 \sim 125[16,27,28]$. A second predictor of efficacy for concentration dependent antibiotic is the ratio $\mathrm{C}_{\max } / \mathrm{MIC}$, considering that values above $8 \sim 10$ would lead to better the clinical results, as well as, to avoid bacterial resistance emergence [11, 12, 28, 38].

The values for $\mathrm{AUC} / \mathrm{MIC}$ ratio and $\mathrm{C}_{\max } / \mathrm{MIC}$ ratio after IM administration were calculated using documented MIC values against Gram-positive and Gram-negative organisms. Although MIC values of enrofloxacin reported for veterinary pathogens Escherichia coli, Haemophilus somnus, Moraexella bovis and Salmonella spp ranged from 0.01 to $0.06 \mu \mathrm{g} / \mathrm{mL}$, Pasteurella multocida and Yersinia spp (usual MICs 0.008 0.01 $\mu \mathrm{g} / \mathrm{mL}$ ) are highly susceptible to the drug $[32,35]$. MIC of enrofloxacin against most veterinary pathogens is reported to be $\leq 0.1 \mu \mathrm{g} / \mathrm{mL}$ [21]. An average $\mathrm{MIC}_{90}$ of $0.1 \mu \mathrm{g} / \mathrm{mL}$ of ENR has been taken into consideration for calculation of efficacy predictors. Following a single IM dose of ENR yielded an AUC/MIC ratio of $(57.02,57.90 \%)$ and $\mathrm{C}_{\max } / \mathrm{MIC}$ ratio of $(11.38,10.5 \%)$, for Baytril and Spectrama Vet, respectively. Thus, ENR given at $2.5 \mathrm{mg} / \mathrm{kg}$ intramuscularly at $12 \mathrm{~h}$ intervals seems to be appropriate for the treatment of diseases of goats caused by pathogens that are highly sensitive to the drug. For treating infections caused by relatively less sensitive bacteria, a higher dose of ENR would be required to achieve the desirable value of AUC/MIC greater than $100 \sim 125 \%$. It has been suggested that the optimal dosage regimens of ENR should be designated to attain the maximum plasma concentration to achieve concentration-dependent killing and suppress the development of drug-resistant bacteria, rather than to extend the amount of time the concentration of the drug in the plasma remains above the MIC for the bacteria $[4,12]$. Based on the above pharmacokinetic and statistical results calculated in the current study, we concluded that Spectrama Vet is bioequivalent to Baytril and both products can be used as interchangeable drug in veterinary medicine practice.

\section{Acknowledgments}

The author wish to thank Dr. Kamil Uney (Department of pharmacology and toxicology, Faculty of Veterinary Medicine, Selcuk University, Turkey) for his advice on the use of 
WinNonlin program.

\section{References}

1. Abo El-Sooud K. Influence of albendazole on the disposition kinetics and milk antimicrobial equivalent activity of enrofloxacin in lactating goats. Pharmacol Res 2003, 48, 389-395.

2. Ahangar AH, Srivastava AK. Pharmacokinetics of enrofloxacin in febrile crossbred bovine calves. Indian $\mathbf{J}$ Pharmacol 2000, 32, 305-308.

3. Alvinerie M, Lacoste E, Sutra JF, Chartier C. Some pharmacokinetic parameters of eprinomectin in goats following pour-on administration. Vet Res Commun 1999, 23, 449455 .

4. Anadon A, Martinez-Larranaga MR, Diaz MJ, FernandezCruz ML, Martinez MA, Frejo MT, Martinez M, Iturbe J, Tafur M. Pharmacokinetic variables and tissue residues of enrofloxcin and ciprofloxacin in healthy pigs. Am $\mathrm{J}$ Vet Res 1999, 60, 1377-1382.

5. Bimazubute $\mathbf{M}$, Cambier $\mathbf{C}$, Baert $\mathbf{K}$, Vanbelle $\mathbf{S}$, Chiap P, Albert A, Delporte JP, Gustin P. Penetration of enrofloxacin into the nasal secretions and relationship between nasal secretions and plasma enrofloxacin concentrations after intramuscular administration in healthy pigs. J Vet Pharmacol Ther 2010, 33, 183-188.

6. Broome RL, Brooks DL, Babish JG, Copeland DD, Conzelman GM. Pharmacokinetic properties of enrofloxacin in rabbits. Am J Vet Res 1991, 52, 1835-1841.

7. Brown SA. Fluoroquinolones in animal health. J Vet Pharmacol Ther 1996, 19, 1-14.

8. Chen ML, Shah V, Patnaik R, Adams W, Hussain A, Conner D, Mehta M, Alinowski H, Lazor J, Huang SM, Hare D, Lesko L, Sporn D, Williams R. Bioavailability and bioequivalence: an FDA regulatory overview. Pharm Res 2001, 18, 1645-1650.

9. Davis JL, Foster DM, Papich MG. Pharmacokinetics and tissue distribution of enrofloxacin and its active metabolite ciprofloxacin in calves. J Vet Pharmacol Ther 2007, 30, 564-571.

10. Dorfman M, Barsanti J, Budsberg SC. Enrofloxacin concentrations in dogs with normal prostate and dogs with chronic bacterial prostatitis. Am J Vet Res 1995, 56, 386-390.

11. Drusano GL, Johnson DE, Rosen M, Standiford HC. Pharmacodynamics of a fluoroquinolone antimicrobial agent in a neutropenic rat model of Pseudomonas sepsis. Antimicrob Agents Chemother 1993, 37, 483-490.

12. Dudley MN. Pharmacodynamics and pharmacokinetics of antibiotics with special reference to the fluoroquinolones. Am J Med 1991, 91, 45S-50S.

13. Elmas M, Tras B, Kaya S, Bas AL, Yazar E, Yarsan, E. Pharmacokinetics of enrofloxacin after intravenous and intramuscular administration in Angora goats. Can $\mathrm{J}$ Vet Res 2001, 65, 64-67.

14. Elmas M, Uney K, Yazar E, Karabacak A, Traş B. Pharmacokinetics of enrofloxacin following intravenous and intramuscular administration in Angora rabbits. Res Vet Sci 2007, 82, 242-245.

15. Elsheikh HA, Taha AA, Khalafallah AI, Osman IA. Disposition kinetics of enrofloxacin (Baytril 5\%) in sheep and goats following intravenous and intramuscular injection using a microbiological assay. Res Vet Sci 2002, 73, 125129.

16. Forrest A, Nix DE, Ballow CH, Goss TF, Birmingham MC, Schentag JJ. Pharmacodynamics of intravenous ciprofloxacin in seriously ill patients. Antimicrob Agents Chemother 1993, 37, 1073-1081.

17. Gibaldi M, Perrier D. Non Compartmental Analysis Based on Statistical Moment Theory Pharmacokinetics, 2nd edn, pp 409-417. Marcel Dekker, New York, 1982.

18. Giguere S, Sweeney RW, Belanger M. Pharmacokinetics of enrofloxacin in adult horses and concentration of the drug in serum, body fluids and endometrial tissues after repeated intragastrically administered doses. Am J Vet Res 1996, 57, 1025-1030.

19. Haddad NS, Pedersoli WM, Ravis WR, Fazeli MH, Carson RL. Combined pharmacokinetics of gentamicin in pony mares after a single intravenous and intramuscular administration. Am J Vet Res 1985, 46, 2004-2007.

20. Haritova A, Lashev L, Pashov D. Pharmacokinetics of enrofloxacin in lactating sheep. Res Vet Sci 2003, 74, 241245.

21. Kaartinen L, Pyorala S, Moilanen M, Raisanen S. Pharmacokinetics of enrofloxacin in new-born and oneweek-old calves. J Vet Pharmacol Ther 1997, 20, 479-482.

22. Kaartinen L, Salonen M, Alli L, Pyorala S. Pharmacokinetics of enrofloxacin after single intravenous, intramuscular and subcutaneous injections in lactating cows. J Vet Pharmacol Ther 1995, 18, 357-362.

23. Kim MS, Lim JH, Park BK, Hwang YH, Yun HI. Pharmacokinetics of enrofloxacin in Korean catfish (Silurus asotus). J Vet Pharmacol Ther 2006, 29, 397-402.

24. Kung K, Riond JL, Wanner M. Pharmacokinetics of enrofloxacin and its metabolite ciprofloxacin after intravenous and oral administration of Baytril in dogs. J Vet Pharmacol Ther 1993, 16, 462-468.

25. Langston VC, Sedrich S, Boothe DM. Disposition of single dose oral enrofloxacin in the horse. J Vet Pharmacol Ther 1996, 19, 316-319.

26. Lewbart G, Vaden S, Deen J, Manaugh C, Whitt D, Doi A, Smith T, Flammer K. Pharmacokinetics of enrofloxacin in the red pacu (Colossoma brechypomum) after intramuscular, oral and bath administration. J Vet Pharmacol Ther 1997, 20, 124-128.

27. Lode H, Borner K, Koeppe P. Pharmacodynamics of fluoroquinolones. Clin Infect Dis 1998, 27, 33-39.

28. Madaras-Kelly KJ, Ostergaard BE, Hovde LB, Rotschafer JC. Twenty-four-hour area under the concentration-time curve/ MIC ratio as a generic predictor of fluoroquinolone antimicrobial effect by using three strains of Pseudomonas aeruginosa and an in vitro pharmacodynamic model. Antimicrob Agents Chemother 1996, 40, 627-632.

29. Nielsen P, Gyrd-Hansen N. Bioavailability of enrofloxacin after oral administration to fed and fasted pigs. Pharmacol Toxicol 1997, 80, 246-250.

30. Ovando HG, Gorla N, Luders C, Poloni G, Errecalde C, Prieto G, Puelles I. Comparative pharmacokinetics of enrofloxacin and ciprofloxacin in chickens. J Vet Pharmacol Ther 19990, 22, 209-212.

31. Ozdemir N, Yildirim M. Bioequivalence study of two 
long-acting oxytetracycline formulations in sheep. Vet Res Commun. 2006, 30, 929-934.

32. Prescott JF, Yielding KM. In vitro susceptibility of selected veterinary bacterial pathogens to ciprofloxacin, enrofloxacin and norfloxacin. Can J Vet Res 1990, 54, 195197.

33. Rao GS, Ramesh S, Ahmad AH, Tripathi HC, Sharma LD, Malik JK. Pharmacokinetics of enrofloxacin and its metabolite ciprofloxacin after intramuscular administration of enrofloxacin in goats. Vet Res Commun 2001, 25, 197204.

34. Rao GS, Ramesh S, Ahmad AH, Tripathi HC, Sharma LD, Malik, JK. Pharmacokinetics of enrofloxacin and its metabolite ciprofloxacin in goats given enrofloxacin alone and in combination with probenecid. Vet $\mathrm{J}$ 2002, 163, 85-93.

35. Schroder J. Enrofloxacin: a new antimicrobial agent. J S
Afr Vet Asso 1989, 60, 122-124.

36. Toutain PL, Koritz GD. Veterinary drug bioequivalence determination. J Vet Pharmacol Ther 1997, 20, 79-90.

37. Vancutsem PM, Babish JG, Schwark WS. The fluoroquinolone antimicrobials: structure, antimicrobial activity, pharmacokinetics, clinical use in domestic animals and toxicity. Cornell Vet 1990, 80, 173-186.

38. Walker RD. The use of fluoroquinolones for companion animal antimicrobial therapy. Aust Vet J 2000, 78, 84-90.

39. Walker RD, Stein GE, Hauptman JG, McDonald KH. Pharmacokinetic evaluation of enrofloxacin administered orally to healthy dogs. Am J Vet Res 1992, 53, 2315-2319.

40. Zechiedrich EL, Cozzarelli NR. Roles of topoisomerase IV and DNA gyrase in DNA unlinking during replication in Escherichia coli, Genes Dev 1995, 9, 2859-2869. 